Individuals, persons and agency theory contrasted views on social interactions at work

Helena Lopes

Setembro de 2014

WP n. ${ }^{\circ} 2014 / 04$

DOCUMENTO DE TRABALHO

WORKING PAPER

DINAMIP'CET

CENTRO DE ESTUDOS SOBREA MUDANCA
SOCIOECONÓMICA E O TERRITÓHIO

ISCTE-IUL 
Individuals, persons and agency theory - contrasted views on social interactions at work

Helena Lopes *

WP n. ${ }^{\circ} 2014 / 04$

DOI: 10.7749/dinamiacet-iul.wp.2014.04

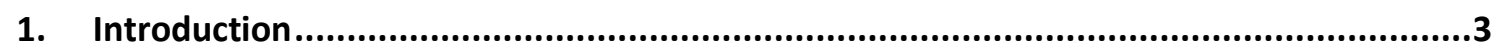

2. The concepts of the individual and the person - application to the sphere of work ........4

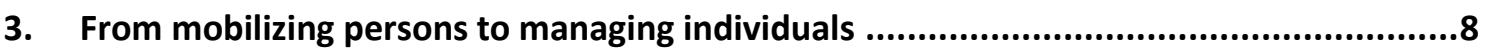

4. Social interactions at work as seen by agency theory ................................................11

5. What is actually at stake is the agency theory's conception of the firm ........................16

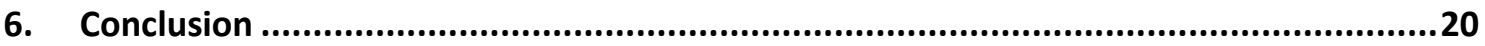

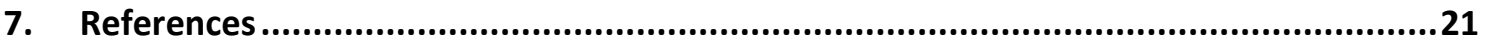




\title{
Individuals, persons and agency theory - contrasted views on social interactions at work
}

\begin{abstract}
The paper draws on the distinction between the concepts of individual and person to show how management rhetoric addresses workers as persons whereas actual management practices organize work as if workers were opportunistic individuals. We argue that this paradox is partly due to the widespread influence of agency theory whose conception of the firm, based on the agency costs generated by the supposedly non-cooperative workers' behavior, became an influential normative model. Our argument is that agency theory's basic assumption powerfully contributed to further and legitimize the ongoing power shift from labor to capital. Major institutional changes in corporate governance regulation are required to make firms' behavior consistent with their rhetoric.
\end{abstract}

Keywords: individuals' vs persons, agency theory, cooperation, contemporary work, management paradoxes, social interactions at work.

"... men, not Man, live on the earth and inhabit the world" (Arendt, 1958:7) 


\section{INTRODUCTION}

The several paradoxes that always marked the world of work had critically grown deeper in the last decades. Pressured by markets and shareholders to simultaneously innovate and reduce costs, firms' management took on a schizophrenic turn. Being aware of the extent to which organizational efficiency depends on the workers' motivation, firms attempt to mobilize the workers' commitment through a trust-building and cooperative rhetoric. But the management practices they actually developed in the last years, based on tightened control and individualized incentives, can but undermine trust and cooperation (Drago and Garvey, 1998).

A close examination of this state of affairs makes one realizes that, whereas management rhetoric addresses workers as persons - that is, relational, socially embedded beings endowed with moral capacity (Harris, 1989), actual management practices address workers as individuals - that is, non-cooperative beings predominantly driven by self-interest. Since real workers are increasingly educated persons rather than mere self-interested individuals, their subjective involvement at work and expectations regarding work have tended to increase which, combined with the paradoxical injunctions referred above, are bringing about an unprecedented deterioration of the quality of work life.

The argument of the present paper is that what underlies the increase in the gap between management rhetoric and practice is the prevailing influence of agency theory on both academics and practitioners. Indeed, agency theory came to form the common theoretical ground of mainstream economic theories of the firm since the 1970s, and it now also dominates other firm-related academic fields (corporate governance, law and economics, accounting and finance, etc). Beyond, or because of, this huge academic influence ${ }^{1}$, agency theory became a powerful normative model with pervasive real-world consequences. The roots of agency theory's influence lie in its few but powerful basic assumptions.

Firstly, agency theory conceives firms as a cascade of principal-agent relationships in which agents seek to maximize their self-interest and act opportunistically whenever possible. Such conception of relationships at work is at odds with the consideration of workers as persons; it is associated with a definition of firms as "nexus of contracts" (Jensen and Meckling, 1976) established among amoral utility-maximizers whose effort must be tightly stimulated and monitored. Secondly, following Friedman (1970)'s seminal paper, agency theory assumes that i) "shareholder value" is the only legitimate goal of the corporate firm because ii) shareholders are

\footnotetext{
1 Jensen and Meckling (1976) is the third most cited paper in economics among those published since 1970; Michael Jensen is the fourth most cited author (Kim et al, 2006).

DINÂMIA'CET - IUL, Centro de Estudos sobre a Mudança Socioeconómica e o Território ISCTE-IUL - Av. das Forças Armadas, 1649-026 Lisboa, PORTUGAL

Tel. 210464031 - Extensão 293100 E-mail: dinamia@iscte.pt www.dinamiacet.iscte.pt
} 
the owners of the firm. Whereas postulate i) has since long been debated in the literature, postulate ii) is less disputed though questionable, notably on legal grounds (Chassagnon and Hollandts, 2014; Robé, 2011, 2012; Blair and Stout, 1999).

Even though agency theory did not directly influence the evolution of work, these assumptions about human behavior and the nature of firms contributed to legitimize the power shift from labor to capital that forms the hallmark of contemporary work. The aim of the present paper is to critically examine agency theory's behavioral assumption and argue that it largely contributed to the intensification of the paradoxes presently undergone by workers.

Our argument is structured as follows. We begin in section Two by highlighting the differences between the concepts of individual and person. We then draw on this distinction to argue that cooperative behavior, which ultimately distinguishes firms from markets, cannot be accounted for without the social and moral abilities of persons. Section Three presents first the management rhetoric aiming at mobilizing "persons" and then the actual management practices aiming at motivating and controlling "individuals". Section Four examines agency theory's conception of social interactions at work and highlights the extent to which it departs from a person-based conception of behavior at work. Section Five relates the argument developed so far to the two other postulates of agency theory referred above and briefly sketches an alternative to the principal-agent/agency costs framework. Section Six concludes.

\section{THE CONCEPTS OF THE INDIVIDUAL AND THE PERSON - APPLICATION TO THE SPHERE OF WORK}

\section{Distinguishing between the person and the individual}

All heterodox economics approaches emphasize the need to replace the mainstream atomistic conception by a socially embedded conception of the individual, but none suggests a change in terminology. In contrast, some philosophers and anthropologists employ different terms to single out these two different views of human beings. The concept of individual stresses the internal attributes and uniqueness of humans primarily conceived as separate while the concept of person adds to these substantive characteristics the recognition of the constitutive social dimension of humans. Whereas individuals are possessors of qualities indigenously describable in abstract terms (see the representation of the utility-maximizing individual by his indifference

DINÂMIA'CET - IUL, Centro de Estudos sobre a Mudança Socioeconómica e o Território ISCTE-IUL - Av. das Forças Armadas, 1649-026 Lisboa, PORTUGAL

Tel. 210464031 - Extensão 293100 E-mail: dinamia@iscte.pt www.dinamiacet.iscte.pt 
map or utility function), persons are agents-in-society influenced by the context in which they live and the persons with whom they interact (Roger, 2012; Harris, 1989).

The supremacy of mainstream economics succeeded in imposing the atomistic, Hobbesian view, in which humans are able to survive and grow outside the world of social interaction. However, other philosophical strands argue that humans are constitutively relational beings since the genesis of the human mind is not mono-logical - something each person accomplishes on her/his own - but dia-logical, something that comes out of the exchanges with others, namely through language (Taylor, 1989). This tradition consequently characterizes the human condition by its gregariousness and its struggle for social recognition; persons enter into relations with others because of their need for relatedness and social esteem (Honneth, 1995). By contrast, rational choice theory retains the Hobbesian struggle for self-preservation as the basic human condition; individuals enter in relation with others when and if they need them to reach their goals, not for the relation itself.

Focusing on humans as persons draws attention to two features crucial for our purpose. Firstly, all concepts of person explicitly emphasize the moral/judgmental capacities of humans. Whereas mainstream economics highlights the calculative abilities of individuals - required for utility maximization - the inter-subjective ontology of persons emphasize their interpretative and normative abilities (Favereau, 2008). Persons are capable of submitting their conduct to shared values and, thus, of committing themselves to common goals and complying with commitments. Only the concept of person, because it breaks with ontological isolation, is theoretically compatible with the idea of a common good, which supposes a commonly shared set of standards and values. Secondly, acknowledging the relational constitution of persons means recognizing their interdependence and vulnerability. Human beings need to relate with others, which makes them vulnerable to others' actions and behavior (Honneth, 1995). This contrasts with the rational economic agent's self-sufficiency.

The need to render behavior predictable - and thereby prone to modeling - led mainstream economists to adopting a view of the individual endowed with stable preferences and self-sufficiency. Even in the models that introduce social and moral motives into utility functions, individuals are calculative rather than gregarious beings. Relating with others and following behavioral norms result from individualistic, possibly enlightened, calculations rather than moral capacity: "We do not assume that people follow a social norm for its own sake, but we investigate how such a rule is sustained by self-interested community members" (Kandori, 1992:63). Individuals as conceived by economists ultimately seek to maximize their utility; they

DINÂMIA'CET - IUL, Centro de Estudos sobre a Mudança Socioeconómica e o Território ISCTE-IUL - Av. das Forças Armadas, 1649-026 Lisboa, PORTUGAL

Tel. 210464031 - Extensão 293100 E-mail: dinamia@iscte.pt www.dinamiacet.iscte.pt 
form groups to further their particular interests, not to fulfill any requirement of their flourishing as human beings.

\section{The relational and moral requirements of cooperative behavior}

The mainstream economics view logically assumes that individuals do not spontaneously engage in cooperative endeavors. Instead, cooperation acquires a social dilemmatic nature in that every individual would be better off if all cooperated, but each individual finds in his selfinterest to shirk on his contribution (Olson, 1971) ${ }^{2}$. Yet, the well-functioning of modern production processes, characterized by high levels of uncertainty, strong interdependence, and limited monitoring possibilities, requires that workers effectively cooperate, that is, requires that workers behave as persons not individuals.

Cooperating implies (a) giving up on one's desire to cheat or exploit cooperative partners and (b) expecting that others will cooperate too. Requisite (a) means that workers must commit themselves to the pursuit of a common goal rather than the one-sided pursuit of selfinterest. Yet, separate, independent and self-interested individuals would only engage in a common goal if it happens to converge with their private interests, not because it is a goal commonly pursued. Requisite (b) means that compliance with commitments and expectations about others' behavior acquire crucial importance. Individuals who do not abide by social norms for their own sake would not expect co-workers to cooperate whenever it goes against their individual interests. It is the endorsement of moral norms that both establish and enforce mutual expectations.

More precisely, workers cooperate because cooperating provides the opportunity to enter into interactions which satisfy the human need for gregariousness. It may be said that cooperating gives rise to "relational goods", defined as the outputs of a communicative, cognitive and affective nature generated by the interpersonal relations one enters into (Bruni, 2008; Gui, 2000; Uhlaner, 1989). A given interaction gives rise to (positive) relational goods only if and when the interacting workers jointly value it. That is, relational goods (friendship, camaraderie, reciprocal helping, etc.) are more than just a combination of private goods; to the extent that they require a common valuation, they go beyond the individualistic derivation of utility. Relational goods explain why workers do not systematically exploit cooperative partners (requisite (a)).

\footnotetext{
2 There are models that show that spontaneous cooperative equilibria are sustainable among selfinterested individuals, but the conditions required, namely complete information about everyone past behavior, efficient sanctioning and continuing interaction, are seldom met in real-world.
}

DINÂMIA'CET - IUL, Centro de Estudos sobre a Mudança Socioeconómica e o Território

ISCTE-IUL - Av. das Forças Armadas, 1649-026 Lisboa, PORTUGAL

Tel. 210464031 - Extensão 293100 E-mail: dinamia@iscte.pt www.dinamiacet.iscte.pt 
Cooperating involves a series of mutual obligations that, depending on whether they are fulfilled or not, result in moral goods/bads (e.g. feeling fairly treated and respected versus deceived and humiliated). Moral goods are hence defined as the outputs of a moral nature generated by the social interactions in which workers enter (Lopes et al, 2009). Moral goods involve and require the common valuation of the norms that guide the actions of the interacting workers. The normative appeal of moral norms derives precisely from them being commonly shared. The fact that moral norms prescribe actions that may lead to acting contrary to selfinterest is of special importance. Indeed, only persons abiding to moral norms can expect others, whom they know share the same norms, to also abide by them even when it runs counter to their interest. The existence of moral goods explains how requisite (b) is met.

To sum up, cooperative behavior at work cannot be accounted for without considering the role that relational and moral goods play in motivating and sustaining cooperation. If cooperation undoubtedly entails a calculative facet, it also inevitably calls for the relational and moral capacity of persons. Only morally able and gregarious persons, not calculative individuals, can enter into moral obligations with others. It is important to note that relational and moral goods stem from both horizontal and vertical interactions, that is, from relations with colleagues as well as with superiors. Relational and moral goods may obviously also be "bads" (animosity, disrespect, resentment, etc), in which case they can be destructive for the workers' well-being and organizational performance. The fact that human beings are persons as defined above does not obviate that they do often behave as self-interested, indeed immoral individuals. It remains that the prevalence of cooperation in workplaces, on which capitalist societies rely to such an extent ${ }^{3}$, requires and implies nurturing both relational and moral goods.

\footnotetext{
${ }^{3}$ The fact that interpersonal relations at work are important and that workers endorse moral norms is often used to manipulate workers and perpetuate oppression in the name of overcoming it (Alvesson and Willmont, 1992).
}

DINÂMIA'CET - IUL, Centro de Estudos sobre a Mudança Socioeconómica e o Território

ISCTE-IUL - Av. das Forças Armadas, 1649-026 Lisboa, PORTUGAL

Tel. 210464031 - Extensão 293100 E-mail: dinamia@iscte.pt www.dinamiacet.iscte.pt 


\section{FROM MOBILIZING PERSONS TO MANAGING INDIVIDUALS}

\section{Firms' appeal to the workers' commitment and subjective involvement}

Firms know that workers, being endowed with moral capacities, are for the most part willing to behave cooperatively rather than opportunistically. To pursue the imperative of profitability, they then try to draw workers into a cooperative endeavor and ask them to invest themselves at work (cognitively but also subjectively and affectively). Indeed, the workers' loyalty might be more efficiently achieved through internalized commitment than through obedience, technical prescriptions and bureaucratic control. As put by Boltanski and Chiappelo (1999), contemporary work requires the mobilization of the "whole person".

The attempts of firms to bind workers to the firms' interests have their academic expression in several strands of literature, among which corporate culture and the human resource commitment model (Francis and Keegan, 2006). Corporate culture is broadly defined as a set of values, norms and beliefs shared by the members of an organization that control and guide how individuals and groups interact with each other. Shared norms - as opposed to technical rules - are not and cannot be directly enforced by hierarchical control but may be fostered by a strong corporate culture. Shared norms are enforced by the members of the group themselves because they encompass behaviors that are essential to effective group functioning. Workers who violate shared behavioral norms may be subject to expulsion or ostracism, which generate affective and cognitive suffering (relational bads). Similarly, the "commitment model" prone by human resource scholars intends to empower workers and induce them to display selfdriven initiative and take more responsibility for monitoring their own behavior (Francis and Keegan, 2006).

These management models explicitly acknowledge that behavior at work is driven by internalized moral norms advocate that firms use the workers' moral capacities in the interest of the firm. The social control resulting from the alignment of workers with organizational values would help firms operate like well-oiled machines without the need for extensive monitoring. Instead of relying on conformity and obedience, contemporary management is supposed to yield high levels of motivation and commitment through the building of strong corporate cultures and high performance work practices. Because work is not only a means to survival but also an opportunity for workers to realize their potential and satisfy their need for social esteem, workers are expected to subjectively engage in their work and devote great amounts of cognitive and emotional resources. Many management models now recognize that the economic world

DINÂMIA'CET - IUL, Centro de Estudos sobre a Mudança Socioeconómica e o Território ISCTE-IUL - Av. das Forças Armadas, 1649-026 Lisboa, PORTUGAL

Tel. 210464031 - Extensão 293100 E-mail: dinamia@iscte.pt www.dinamiacet.iscte.pt 
depends on the social and moral abilities of persons, not simply the pecuniary motives of individuals, for its functioning.

Note that strong corporate cultures and commitment models imply giving greater leeway to workers, which means enhancing autonomy at work, decentralizing and involving workers in decision-making, stimulating initiatives and risk-taking, promoting team work, allocating above-market pay (efficiency wages) and ensuring job security. These practices would foster a kind of relation between workers and the organization based on "partial-gift exchanges" (Akerlof, 1982), in which workers reciprocate in effort and dedication the good working conditions offered by the firm. If firms fail to comply with their engagements, workers disengage from the moral obligations that such practices are supposed to generate.

\section{Firms' actual practices: the depersonalization and individualization of work}

However, evidence shows that actual firms' practices break the "psychological contracts" presumed in the corporate culture and human resource rhetoric (Thompson, 2013). In the last decades, firms have managed workers more as if they were maximizing individuals than morally able social persons. The trends that characterize the world of work to-day are in plain contradiction with the rhetoric of trust-building and empowerment of workers ${ }^{4}$ : rising wage inequalities; individualization of performance targets, appraisal schemes and wages; intensification of work; increasing levels of stress and emotional exhaustion; substitution of extrinsic by intrinsic motivations; extension of reporting procedures; expansion of monitoring devices; dissolution of collective solidarities, etc.

These phenomena have made workers actively contribute to the considerable intensification of work observed in the last two/three decades (Lopes et al, 2014). They have resulted in increasing levels of stress and emotional exhaustion, substitution of extrinsic for intrinsic motivations and the dissolution of collective solidarities. Intensification of work is reported as being accompanied by a decrease in the time available for socializing - fewer "nonproductive" moments; less time to learn, teach or help; fewer opportunities to meet and communicate; increasing feelings of isolation - as well as by a general depersonalization and deterioration of work relations (Le Gall, 2011).

Mention must be made of the evolution of autonomy at work as perceived by workers

\footnotetext{
${ }^{4}$ We may add to these trends those of the evolution of employment, marked by depressive labor markets and the decline of security of employment, investment in human capital, career ladders, etc.

DINÂMIA'CET - IUL, Centro de Estudos sobre a Mudança Socioeconómica e o Território ISCTE-IUL - Av. das Forças Armadas, 1649-026 Lisboa, PORTUGAL

Tel. 210464031 - Extensão 293100 E-mail: dinamia@iscte.pt www.dinamiacet.iscte.pt
} 
because this lies at the core of the commitment and corporate culture models, which recommend giving workers more influence at work. Instead of increasing over time and space, as might be expected, perceived work autonomy decreased or remained stable in most European countries in the 1995-2010 period (Lopes et al, 2014). Work autonomy declined markedly for workers in low-skill jobs in all but Nordic countries and it remained more or less stable for high-skill clerical workers in the 15 countries studied. These findings suggest that, overall and in spite of the higher educational level, the changes in work organization during the last two decades have led to a decrease in the influence that most workers now perceive they have over when, how and what to do at work when compared to the early 1990s.

This evolution can only contribute to the dismantling of communal values such as trustworthiness, cooperative dispositions and community building, that underpin the management models referred above.

\section{A double paradox}

The phenomena and considerations described above reveal two paradoxes. The first concerns managerial practices: contemporary capitalism needs the cooperation and subjective involvement of workers but firms' actual practices prompt competition rather than cooperation. The second paradox concerns workers: in spite of their worsening working conditions, workers' attachment to work does not seem to diminish.

Let's begin by the first, managerial paradox. The observation of unfulfilled "psychological contracts", that is, of a gap between managerial words and deeds, is nothing new. Management rhetoric advocates risk taking, personal commitment and trust-building, but in practice firms invest in ever more sophisticated surveillance and control devices such as quantitative and individualized target setting and performance rankings. This paradox meets the person-individual distinction: firms want workers to involve themselves at work as persons but they organize work as if workers were opportunistic individuals, in need of being tightly directed and monitored. By individualizing incentives, controls and rewards, firms rely on the narrow self-interest of workers rather than on their trustworthiness and cooperative dispositions. Social interactions at work come to be regulated by competition. Rivalry and envy rather than mutual trust and reciprocity.

The paradox confronted by workers is particularly cruel. Work became in our societies a powerful generator of identity and self-respect. Many sociological studies testify that the 
workers' expectations of self-actualization and recognition at work increased notably in the last decades, due to increasing educational levels but also to the commodification of other spheres of social life (Carvalho and Rodrigues, 2008). The individualization and depersonalization of work environments hence created a tension between the need for a meaningful work, which necessarily includes feeling to contribute to a common goal and being part of a social community, and the pressure to enter into a competitive, zero-sum game. On the one hand, workers involve themselves as persons in work ${ }^{5}$ but, on the other hand, they are compelled to behave as self-centered individuals to meet the quantitative objectives fixed by management, contributing hence to eroding the collective and cooperative spirit needed for their psychological well-being.

Workers' vulnerability and psycho-social disorders have considerably intensified due to this state of affairs (Siegrist, 2006). Burn-out and stress, feelings of culpability when performance targets are not met, and feelings of isolation became prevalent phenomena of contemporary workplaces (Le Gall, 2011). Never before has the person-side of workers been so exploited and disrespected. Our argument is that this evolution of the world of work does not merely result from myopic managerial choices; it stems from the dominance of agency theory and the transformation of the latter's postulates into a dominant ideology and normative model (Goshal, 2005).

\section{SOCIAL INTERACTIONS AT WORK AS SEEN BY AGENCY THEORY}

\section{Social interactions as costly contractual exchanges}

The management practices described so far (enhanced control, individualization of work, performance-related wages) closely follow agency theory's prescriptions. These prescriptions derive logically from the behavioral assumption of individualistic utility-maximization, which in turn logically assumes potentially opportunistic behavior. Consequently, the core concept of agency theory is agency costs, that is, the costs generated by the likely shirking of workers, their providing low levels of effort (because work generates disutility) and their taking decisions that further their interests rather than that of the firm.

\footnotetext{
${ }^{5}$ It must be noted that workers may be committed towards their work but not towards the organization in which they work (Cushen and Thompson, 2012), which further amplifies the paradoxical situation and its deleterious effects.
}

DINÂMIA'CET - IUL, Centro de Estudos sobre a Mudança Socioeconómica e o Território

ISCTE-IUL - Av. das Forças Armadas, 1649-026 Lisboa, PORTUGAL

Tel. 210464031 - Extensão 293100 E-mail: dinamia@iscte.pt www.dinamiacet.iscte.pt 
It is a particular kind of social interactions at work, namely principal-agent relationships, that grounds the whole theoretical apparatus of agency theory. Firms are conceived as a cascade of sequential principal-agent contracts in which principals delegate work to agents to act and decide on their behalf. This delegation allows agents to act opportunistically, which creates the well-know moral hazard situation ${ }^{6}$. Firms are nothing more than "nexus for a set of contracting relationships among individuals" (Jensen and Meckling, 1976:310). The contractual relationships that take place within the firm are of the same nature than market transactions: employers are not supposed to have any contractual obligation to long-term relationships with employees and the latter are assumed to be morally insensitive individuals who eventually renege on commitments. In the first agency models, only the vertical relationships, those of a principal-agent nature, were deemed of interest in the production process, each supervisor acting as a principal in relation to his subordinates and an agent to his own supervisor.

Horizontal interactions ${ }^{7}$ among co-workers were nonetheless soon acknowledged in the literature, under the label of side-contracting. In the eyes of the then leading agency theorists, side-contracting takes the form of "bribes, personal relationships and promises of reciprocation" (Holstrom and Tirole, 1989:94). These "contracts" agents enter into cannot be fully controlled by principals, which generate agency costs and add "costly constraints to the owners' optimization problem" (Holstrom and Tirole, 1989:3). Side-contracting is hence considered undesirable and firms must take measures to prevent it. Suggested measures include the limitation of personal relationships, through isolation, for example, and the restriction of reciprocity through the promotion of short-term relationships (Holstrom and Tirole, 1989). Though, these authors comment in passing that the measures they recommend may have organizational drawbacks since they may undermine the development of trust, which they view as crucial for cooperation. In subsequent papers, side-contracting is considered as taking two possible forms, collusion or cooperation, depending on its effect on the organization. The incentive and organizational structure should then regulate the degree of cooperation in order to limit collusion. In sum, employers cannot but be suspicious towards social interactions among workers.

These radical assumptions about horizontal interactions at work smoothened somewhat

\footnotetext{
6 Before the 1970s, the relationship between employer and employee was not seen as particularly problematic in standard economics. Employees were simply to be remunerated according to their marginal productivity. It was agency theory and its postulate of opportunistic individuals which put at the center of the theory of the firm the notions of agency costs and moral hazard.

7 Observational studies reveal that most workers spend the majority of their time interacting with peers rather than with supervisors and subordinates. This illustrates the crucial role of horizontal coordination and relational goods for cooperation.
} 
after the advent of experimental and behavioral economics. Some principal-agent models began to explicitly acknowledge that workers derive utility from cooperation (defined as reciprocal helping) and that cooperative behavior among workers is a source of competitive advantage for organizations (Rob and Zemsky, 2002). It is recognized that "preferences for cooperating" are partly endogenous, which means that cooperative behavior may and should be fostered by appropriate incentive systems.

Likewise, if the first agency theory models assumed that workers behave a- or immorally towards principals, in recent years, some agency theorists began to elaborate on Akerlof (1982)'s view of labor contracts as partial gift exchange. Dur et al (2010) call attention to the many benefits good relations between principals and agents may yield to the firm and emphasize the fact that such relations may motivate workers more powerfully than pecuniary incentives. Employees' effort and employer's benevolent treatment of workers are modeled as reciprocal gifts, and the signaling of good intentions on the part of principals, though costly, appears as a possibly efficient strategy (Non, 2012).

Although these developments of agency theory denote an improvement in the way social interactions at work are envisaged, they differ to a great extent from the perspective endorsed here. To begin with, cooperation is not actually considered a collective/social endeavor; the decision to cooperate is taken separately by each worker depending on his/her preferences. Yet, as argued by Hodgson (2013), cooperating cannot be accounted for by introducing ad-hoc preferences into individualistic utility functions. Rather than a constitutive trait of human conduct, cooperating is viewed by agency theorists as a residual kind of behavior: "voluntary cooperation is defined as the difference between actual and privately optimal effort" (Non, 2012: 322). Secondly, instead of relational goods, sought and valued for their own sake by both employees and supervisors, social interactions are considered socioemotional resources that are costly to produce and regulate. Good relations at work are always envisaged instrumentally, as a tool to foster efficiency, rather than an end in itself. Lastly, the agency models that take cooperative dispositions into consideration remain an exception and social preferences are always introduced in an ad-hoc way into the individualistic theoretical apparatus. For agency theorists, relational goods do not stem from the social interactions associated to joint production but from the satisfaction of individual preferences. The legitimacy of the individualistic utility-maximizing assumption is never questioned.

Another feature of the principal-agent models that take non-pecuniary motives into account is worth mentioning: they always end up recommending low-powered incentives, that is, reduced wages. Two explanations are advanced. Firstly, as cooperating increases the 
workers' utility, firms may offer lower wages - relational goods substitute for incentives and allow for a reduction in compensation. Secondly, since monetary incentives are acknowledged to crowd-out intrinsic motivations, that is, spontaneous cooperative behavior, incentive pay schemes are "inefficient". In brief, though cooperating is crucial for the efficient functioning of firms, the workers who cooperate receive lower pecuniary compensation. Akerlof (1982)'s insight that gift-exchange relationships result from above-market wages has been turned upside down - which is but one sign of the perversity of agency theory's prescriptions.

\section{The perverse effects of agency theory's prescriptions - when a false theory threatens to become true}

To minimize the agency problems supposed to originate from the workers' opportunistic behavior, agency theory prescribes two kinds of arrangements (Jensen and Meckling, 1976): i) compensation schemes aimed at aligning the principal and agents' interests (particularly recommended for high corporate executives) and ii) control devices aimed at keeping selfserving behavior in check and providing information about what agents are actually doing. Both arrangements would curb agents' opportunism since they reduce the conflicts of interest and prevent agents from deceiving principals. But the widespread implementation of these prescriptions may be at the root of the decline in perceived work autonomy reported above.

These practices may have even more deleterious counterproductive effects: instead of mitigating opportunistic behavior, they may actually create and enhance such behavior (Goshal, 2005; Roberts, 2005). The use of strict control devices signals to workers that they are not trusted, which may result in them becoming less trustworthy. Indeed, strict monitoring is shown to threaten the sense of personal autonomy, thereby damaging self-esteem and decreasing intrinsic motivation (Gagné and Deci, 2005). When workers are excessively controlled, intrinsic motivation is supplanted by defensive or self-protective processes such as the tendency to withdraw concern for others and focus on oneself (Deci \& Ryan 2000). Workers then tend to adhere to more materialistic values and behave less cooperatively. Sheldon et al (2004) show that workers involved in controlling environments appear less satisfied at work and more focused on pay and benefits.

In the same vein, the use of monitoring tools by managers leads them to distrust workers and triggers a pathological spiral. These processes are well-known by psychologists: "Surveillants come to distrust their targets as a result of their own surveillance and targets in fact become unmotivated and untrustworthy. The target is now demonstrably untrustworthy and 
requires more intensive surveillance, and the increased surveillance further damages the target. Trust and trustworthiness both deteriorate" (cited in Goshal, 2005: 85). This problem also concerns top executives whose compensation schemes are recommended to be aligned with shareholder's interests. Many of the reforms set up to curb top executives' opportunism in the last decades ended up augmenting rather than diminishing the governance problem (Roberts, 2005). As Hannah Arendt (1958) brilliantly put, the danger with theories is not so much that they are false, it is that they may become true. In assuming that people behave opportunistically and are primarily motivated by pecuniary motives, agency theory may contribute to make people behave just like that.

The management prescriptions that logically derive from agency theory may hence undermine cooperative and other moral and pro-social dispositions. This is not seen as a problem by agency theorists who, in reducing social interactions to contracts and defining firms as "privately owned markets" (Alchian and Demsetz, 1972: 795), are in fact claiming that the well functioning of firms does not require morally-driven behavior. A strand of agency theory literature acknowledges the vital role of "relational contracts", defined as informal agreements and unwritten codes of conduct, in enforcing incomplete contracts and complying with commitments (Baker et al, 2002). But, despite the term "relational", such contracts are deprived of any kind of personal or social ties. They are plainly impersonal relationships in which the honoring of contracts is exclusively based on self-interested calculations. Baker et al (2002:7475)'s models provide the incentive payments that comprise the "necessary and sufficient condition for the relational-employment contract to be self-enforcing". The social constitution and moral endowment of workers is therefore not necessary for contracts to be honored.

The argument developed in the present paper, namely that relational and moral dispositions are the basis for well-functioning organizations, claims just the opposite. One of the basic distinguishing features of firms when compared to markets is that firms provide the opportunity for intensive interpersonal relationships. It is precisely the unspecified obligations and the exchange of socio-emotional benefits deriving from social interactions that contribute to generating the desire to cooperate and render cooperation sustainable. But agency theorists discard the social and moral dimension of work because they would like to free economic agents from moral obligations and social ties. More specifically, the economic agents that agency theory would like to free from any moral obligation are the shareholders.

DINÂMIA'CET - IUL, Centro de Estudos sobre a Mudança Socioeconómica e o Território

ISCTE-IUL - Av. das Forças Armadas, 1649-026 Lisboa, PORTUGAL

Tel. 210464031 - Extensão 293100 E-mail: dinamia@iscte.pt www.dinamiacet.iscte.pt 


\section{WHAT IS ACTUALLY AT STAKE IS THE AGENCY THEORY'S CONCEPTION OF THE FIRM}

\section{The ownership and governance/responsibility postulates}

We have seen that the features of contemporary work strikingly conform to the way in which agency theory conceives of economic behavior and social interactions at work. Definitely, agency theory is presently much more than a purely positive conception of firms; it became a normative model that largely influences the way in which work is organized (Goshal, 2005). But two other basic postulates of agency theory also powerfully contributed to the present state of affairs, namely: i) the ultimate goal of principals/managers is the maximization of shareholders' interests (measured by the market value of the shares) because ii) shareholders are the owners of firms. These postulates conferred academic legitimacy to the growing adoption of the "shareholder value governance model" witnessed over the last thirty years. By pressuring managers to focus on creating value for shareholders, this governance model submitted firms to the imperative of financial profitability, thereby neglecting workers' well-being and bringing about the dramatic loss of power labor is presently undergoing (Fligstein and Shin, 2004). Shareholders' interest would prevail over workers' rights; labor costs were to be minimized.

The ownership postulate (ii)) supports the principal-agent view of corporate firms, as stated by Friedman (1970:2): "a corporate executive is an employee of the owners of the business". A few agency theorists, though, do not endorse this postulate: "ownership of capital should not be confused with ownership of the firm" (Fama, 1980:290). Indeed, the firm and the corporation must be distinguished: the firm is an organized economic activity with no juridical personality - it can hence not be owned - while the corporation is a legal subject used to legally structure the firm - it cannot be owned either, only the shares it issues can be ${ }^{8}$. Shareholders enjoy the privileges of the owner only towards what they own - the shares -, they cannot have these privileges towards the corporation having issued the shares, and much less so towards the firm. The ownership postulate is founded on a misunderstanding of the actual content of corporate law (Robé, 2011, 2012; Favereau and Robé, 2012; Blair and Stout, 1999).

Since the ownership postulate does not hold, postulate i), also uttered by Friedman (1970) - the primary responsibility of managers is to shareholders -, also drops, which implies that managers are responsible not just to shareholders but to all the contributors of resources to the firm, first and foremost workers. Actually, corporate law never refers to any legal duty to

\footnotetext{
${ }^{8}$ These considerations only apply, obviously, to public corporations, not individually-owned firms.

DINÂMIA'CET - IUL, Centro de Estudos sobre a Mudança Socioeconómica e o Território

ISCTE-IUL - Av. das Forças Armadas, 1649-026 Lisboa, PORTUGAL

Tel. 210464031 - Extensão 293100 E-mail: dinamia@iscte.pt www.dinamiacet.iscte.pt
} 
maximize profits; it only establishes the duty to manage in the "corporate interest", not the shareholders' interest.

Faced with this ownership problem, agency theorists developed in the last years an economic justification for the principle of shareholder value maximization, according to which the best way to ensure economic efficiency is to consider managers the agents of shareholders. The "nexus of principal-agent contracts" definition of the firm would then be preserved and the issue of ownership is deemed irrelevant. However, the fact that shareholders own the shares issued by the corporation but not the corporation itself has very significant consequences, since, as referred, the responsibility of managers then go beyond that of maximizing shareholders' interest to encompass the interests of all resources contributors (Roger, 2012).

In this context, firms cannot any more be conceived as cascades of principal-agents relationships in which the sole relevant problems are those of agency costs and the sole relevant prescriptions are the design of appropriate devices to align managers and shareholders' interests. An alternative theory of the firm is needed, which would revolve around concepts other than that of agency costs.

\section{Sketching some hints for an alternative}

Our intent here is merely to give some of the elements that should be taken into account by alternative(s) theory(ies) of the firm. To begin with, and in accordance with the theoretical considerations made above, a meaningful theory of the firm would follow Barnard's definition of firms as "systems of cooperative services of persons" rather than the "sum of services of individuals" (Barnard, 1938: 110, our italics). That is, the behavioral assumption to be put at the core of the theory of the firm should consider both the cooperative and self-interested dimensions of human behavior. Because it is the possibility of cooperation that justifies the existence of firms in the first place, as claimed by institutionalists and Alchian and Demsetz, the theory's prescriptions would focus on fostering cooperative dispositions rather than trying to economize on, and indeed discard, agent's moral and social capacities.

But preventing firms and workers from being caught ever more deeply in the paradoxes described above cannot be left to managerial perspicacity or the self-regulating capacities of boards or markets. Evidence shows that the failure of commitment models to yield the expected positive outcomes on productivity and workers is due to the insufficient participation of workers in decision-making (Godard, 2004). A full implementation of the commitment model or a 
consistent corporate culture demands that much voice and power is given to workers, which most employers are not prone to do and this, because they do not have to.

The empirical solution to the contemporary degrading of work cannot be purely organizational. Institutional changes that foster the workers' rights and challenge the shareholder primacy norm are called for. The required institutional innovations must reinforce workers' rights rather than dismantle them, as in the newly created "employee shareholder contract" in the UK (Prassl, 2013). The imbalance of power embodied in the institutional structure of the employment relationship is ultimately associated to the non-cooperative behavioral assumption. Changing the latter should stimulate a reduction in both the vulnerability and subordination condition of workers. The workers' needs go beyond the extrinsic dimensions of wages or decent working hours to encompass the psycho-social work environment. The changes in labor law should be necessarily complemented by a change in corporate law that would promote the workers' rights in the governing structure of corporate firms. Our analysis hence leads to recognizing the need for juridical and economic institutions able to regulate firm governance, which is precisely what the launching of agency theory wanted (and succeeded) to avoid in the early seventies (Gindis, 2013).

Inspiration for both the behavioral assumption and institutional framework (involving both labor and corporate law) that would underlie alternative theories of the firm might be found in the common law concept of fiduciary relationship ${ }^{9}$, instead of the now prevalent principalagent relationship. Fiduciaries are ethical relationships of trust between two or more parties who are assumed to be moral actors rather than selfish utility maximizers. "The moral theme in fiduciary regulation is an important part of fiduciary law" (Frankel, 1983:830). Frankel (1983) sharply differentiates the world of contracts - in which each party distinguishes her interests from those of others and acts on her benefit - from that of fiduciaries - who are expected to further the interests of another party rather than their own (which is what workers are actually supposed to do).

Very substantial normative consequences would ensue for how work is to be organized. While the norm of self-interest calls for devices aimed at restraining opportunism, the norm of trust in fiduciary relationships requires that monitoring and control devices, though necessary, do not undermine trust and intrinsic motivations. In arrangements categorized in law as agency, entrustors control their fiduciaries in the performance of their services; in arrangements

\footnotetext{
${ }^{9}$ http://www.law.cornell.edu/wex/fiduciary duty 
categorized as trust, fiduciaries are entrusted with power and enjoy broader discretion to carry out their tasks.

As it could be expected, law and economics scholars deny the distinct nature of fiduciary relationships, which in their view "have no moral footing; they are the same sort of obligations, derived and enforced in the same way, as other contractual undertakings" (Easterbrook and Fischel, 1993: 429). This rationale meets agency theory's theoretical attempt to free principal-agents relationships from moral obligations but stands in sharp contrast to firms' management rhetoric. Real-world firms do persist in their effort to mobilize the "whole person" in workers, which means that they do not (cannot) renounce expecting that workers behave as "fiduciaries" - being loyal to their employer; conducting themselves in a trustworthy and cooperative manner; honoring the non-contracted obligations inherent in incomplete contracts, etc. Why doesn't agency theory account for what exists in reality?

The answer is quite straightforward: because it would jeopardize agency theory's theoretical apparatus. To acknowledge the moral dimension in "principal-agent" relationships, that is, to recognize that workers are persons and not just individuals, would imply recognizing that social interactions in firms differ from market contracting, which in turn would undermine the nexus of contracts definition of the firm. This definition of firms denies the collective nature of production: "we believe the emphasis that [Alchian and Demsetz (1972)] place on joint production is too narrow and therefore misleading. Contractual relations are the essence of the firm [...] joint production can explain only a small fraction of the behavior of individuals associated with a firm" (Jensen and Meckling, 1976:8). Yet, firms are social entities that cannot be reduced to the sum of the individuals who comprise them since production requires that these constitutively social individuals enter into complex and continual interactions. In reducing firms to markets, agency theory wanted to free economic agents from the need for personal relationships and thereby from the fragility of relational and moral goods. But the only way to keep this fragility in check is to create appropriate institutional frames.

DINÂMIA'CET - IUL, Centro de Estudos sobre a Mudança Socioeconómica e o Território

ISCTE-IUL - Av. das Forças Armadas, 1649-026 Lisboa, PORTUGAL

Tel. 210464031 - Extensão 293100 E-mail: dinamia@iscte.pt www.dinamiacet.iscte.pt 


\section{CONCLUSION}

Our point of departure was the observation of an increasing contradiction between management rhetoric - which tries to draw workers into a collective, cooperative endeavor - and management practices - which continually reinforce control and rely on individualistic, market-type incentives. We argue that the increase in this contradiction - itself inherent to capitalism - is associated to the widespread influence of agency theory, and specifically to its success in turning into influential normative models the basic assumptions on which it is grounded. Its conception of human agency, based on the assumption of self-interested, opportunistic, behavior, combined with the ownership postulate and the related governance prescriptions powerfully contributed to enhancing the pressure for financial profitability and labor costs reduction, thereby weakening the power of workers and degrading the psychosocial work environments.

We draw on the distinction between the concepts of individual and person to show that management rhetoric addresses workers as persons but actually organizes work as if workers were opportunistic individuals. While the concept of individual defines humans as unique and separate beings engaged in the pursuit of self-centered goals, the concept of person defines them as constitutively social, morally-endowed beings prone to cooperative behavior because of their need for gregariousness. We then show that cooperation, on which the well-functioning of modern productive processes depends, as acknowledged in management rhetoric, would not be sustainable among "pure" individuals. Indeed, cooperating implies i) giving up on one's desire to exploit partners and ii) expecting that others cooperate too. Why and how would individuals satisfy these requisites? In contrast, because they value social interactions and because they endorse shared moral norms, persons cooperate even when it runs counter to their interest.

Agency theory's disregarding of the relational and moral dimensions of workers is consistent with its definition of firms as nexus of contracts, which equates social interactions at work to market interactions and denies the collective character of production. Like neoclassical economics, agency theory wants to free economic agents from - the vulnerability of - moral obligations and social ties. Its prescriptions, aimed at constraining and aligning self-interested individuals, indirectly but powerfully molded the processes of individualization and depersonalization that mark contemporary work. Beyond their deeply deleterious effects on the workers' health and well-being, these processes are fostering the opportunism they were supposed to restrain.

DINÂMIA'CET - IUL, Centro de Estudos sobre a Mudança Socioeconómica e o Território

ISCTE-IUL - Av. das Forças Armadas, 1649-026 Lisboa, PORTUGAL

Tel. 210464031 - Extensão 293100 E-mail: dinamia@iscte.pt www.dinamiacet.iscte.pt 
Recognizing that the good working of firms and their creativity necessitates treating workers as persons rather than individuals, combined with accepting that shareholders cannot be said to own corporate firms, leads to questioning the legitimacy of the power of the owners of capital in corporate firms and thereby their governance structure and responsibilities. In order to coerce firms to be more consistent with their own rhetoric, major institutional changes are required.

\section{REFERENCES}

ALCHIAN, A., and Demsetz, H., (1972), Production, information costs and economic organization, American Economic Review, LXII(2): 777-795.

AKERLOF, George, (1982), Labor contracts as partial gift exchange, The Quarterly Journal of Economics, 97(4): 543-569.

ARENDT, H., (1958): The Human Condition, Chicago: University of Chicago Press.

ALVESSON M., and Willmont H., (1992), Critical management studies, London: Sage Publications.

BAKER, G., Gibbons, R., and Murphy, K. J., (2002), Relational contracts and the theory of the firm, The Quarterly Journal of Economics, 117(1): 39-84.

BARNARD, C., (1938), The functions of the executive, Cambridge: Harvard University Press.

BLAIR, M., and Stout, L.; (1999), A team production theory of corporate law?, Journal of Corporation Law, 24(4): 751-807.

BOLTANSKI, Luc ; and Chiapello, E. ; (1999), Le nouvel esprit du capitalisme, Paris: NRF, Gallimard.

BRUNI, L.; (2008), Back to Aristotle? Happiness, Eudaimonia, and Relational Goods. in Bruni, Comim and Pugno (ed) Capabilities and Happiness. Oxford: Oxford University Press. 
CARVALHO, L., and Rodrigues, J., (2008), Are markets everywhere? Understanding contemporary processes of commodification, in Davis J and W. Dolfsma, The Elgar Companion to Social Economics, Cheltenham: Edward Elgar.

CHASSAGNON, V.; and Xavier, H.; (2014), Who are the owners of the firm: shareholders, employees or no one?, Journal of Institutional Economics, 10(1): 47-69.

CUSHEN, J., and Thompson, P.; (2012), Doing the right thing? HRM and the angry knowledge worker, New Technology, Work and Employment, 27(2): 79-92.

DECI, E., Ryan, R.; (2000), The 'what' and 'why' of goal pursuits: Human needs and the selfdetermination of behavior. Psychological Inquiry, 11: 227-268.

DRAGO, R., and Garvey, G. T., (1998), Incentives for Helping on the Job: Theory and Evidence, Journal of Labor Economics, Vol. 16, No. 1, pp. 1-25.

DUR, R., Non, Arjanand, Roelfsema, Hein, (2010), Reciprocity and incentive pay in the workplace, IZA Discussion Paper nº 4782.

EASTERBROOK, F., and Fischel, D., (1993), Contract and fiduciary duty, Journal of Law and Economics, 36:425-46.

FAVEREAU, O.; (2008), The unconventional, but conventionalist, legacy of Lewis's “convention". Topoi. 27(1): 115-126.

FAVEREAU, O., and Robé, J.P., (2012), Responsabilité sociale de l'entreprise et propriété de la firme, in Allouche J (dir.), Encyclopédie des ressources humaines, Paris, Vuibert, pp. 127785.

FLIGSTEIN, N., and Shin, T., (2004), The shareholder value society: A review in changes in working conditions in US, 1976-2000, in K. Neckerman (ed.), Social Inequality, New-York: Russell Sage.

FRANCIS, H. and Keegan, A., (2006), The changing face of HRM: in search of balancee, Human Resource Management Journal, 16, 3, 231-249.

FRANKEL, T., (1983), Fiduciary law, California Law Review, 71(3): 795-836. 
FRIEDMAN, M., (1970), The social responsibility of business is to increase its profit, The New York Times magazine, September 13, 1970.

GOSHAL, S., (2005), Bad management theories are destroying good management practices, Academy of management Learning and Education, 4(1): 75-91.

GUI, B., (2000), Beyond transactions: on the interpersonal dimensions of economic reality. Annals of Public and Cooperative Economics. 71(2): 139-169.

HARRIS, G., (1989), Concepts of individual, self, and person in description and analysis, American Anthropologist, vol. 91, pp. 599-612.

HODGSON, G., (2013), From pleasures machines to moral communities, Chicago: The University of Chicago Press.

HOLSTROM, B., and Tirole, J. (1989), The theory of the firm, in Schmalensee R. and R. Willig (ed.) Handbook of Industrial Organization vol. 1, Amsterdam: North-Holland/Elsevier.

HONNETH, A., (2005), The struggle for recognition - The moral grammar of social conflicts, Cambridge: Polity Press.

JENSEN, M., and Meckling, W., (1976), The theory of the firm: managerial behavior, agency costs, and ownership structure, Journal of Financial economics, vol. 3 (4), pp. 305-360.

KANDORI, M. (1992), Social norms and community enforcement, Review of Economic Studies, 59(1), pp. 63-80.

KIM HAN, E., Morse, A., and Zingales, L., (2006), What has mattered to economics since 1970, Journal of Economic Perspectives, 20(4): 189-202.

LE GALL, Jean-Marc, (2011), L'entreprise irréprochable, Paris: Desclée de Brower.

LOPES H., Santos, A., Teles, N., (2009), The motives for cooperation in work organizations? Journal of Institutional Economics, 5(3): 315-338.

LOPES, H., Lagoa, S., Calapez, T., (2013), Decling autonomy at work in the EU and its effect on civic behavior, Economic and Industrial Democracy, 35(2): 341-366.

DINÂMIA'CET - IUL, Centro de Estudos sobre a Mudança Socioeconómica e o Território ISCTE-IUL - Av. das Forças Armadas, 1649-026 Lisboa, PORTUGAL 
NON, A., (2012), Gift-exchange, incentives and heterogeneous workers, Games and Economic Behaviour, 75(1): 319-336.

ROB, R., and Zemsky, P., (2002), "Social capital, corporate culture, and incentive intensity." RAND Journal of Economics 33, 2 243-257.

JOHN, R., (2005), Agency theory, ethics and corporate governance, in Lehman C. (ed), Advances in public interest accounting, vol.11, Amsterdam: Elsevier, pp. 249-269.

ROGER, B., (ed.) (2012): L'entreprise, formes de propriété et responsabilités sociales, Paris: Éditions Lethilieux.

SHELDON, K., Ryan, R., Deci, E., \& Kasser, T., (2004), The independent effects of goal contents and motives on well-being. Personality and Social Psychology Bulletin, 30(4): 475486.

SIEGRIST, J., (2006), Work, health and welfare: new challenges, International Journal of Social Welfare, 15 (Suppl.1): S5-S12.

TAYLOR, C., (1989), Sources of the self, Cambridge: Cambridge University Press.

THOMPSON, P., (2013), Financialization and the workplace: extending and applying the disconnected capitalism thesis, Work, Employment and Society, 27(3): 472-488.

UHLANER, C., (1989), Relational goods and participation: Incorporating sociality into a theory of rational action, Public Choice, 62: 253-285. 